Trakya Eğitim Dergisi

Cilt 10, Sayı 1

Ocak 2020, 183-193

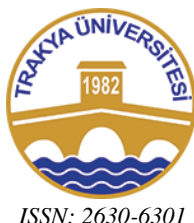

ISSN: 2630-6301
Trakya Journal of Education

Volume 10, Issue 1

January 2020, 183-193

\title{
MEB Öğretmen Yetiştirme Genel Müdürlüğü'nün Hizmet İçi Eğitim Faaliyetleri: Katılımcılar, Eğitim Durumları, Eğitim Konuları
}

\author{
In-service Training Activities of MoNE General Directorate of Teacher Training: \\ Participants, Educational Status, Training Subjects
}

\section{Metin KAYA ${ }^{1}$}

Öz: Bu çalışmanın amacı Türkiye'de Öğretmen Yetiştirme ve Geliştirme Genel Müdürlüğü'nün yürüttüğü öğretmenlere yönelik hizmetiçi eğitim planlarını çeşitli değişkenlere göre incelemektir. $\mathrm{Bu}$ değişkenler hizmetiçi öğretmen eğitimine ilişkin katılımc profili, faaliyet yeri, öğretim biçimi, eğitim kategorileri ve konularıdır. $\mathrm{Bu}$ çalışma nitel araştırma yöntemlerinden durum çalışması yöntemine göre desenlenmiştir. $\mathrm{Bu}$ çalışmanın evreni 2001-2018 yılı Hizmetiçi eğitim planıdır. Bu çalışmada amaçlı örnekleme yöntemlerinden kolay ulaşılabilir örnekleme yöntemine göre 2018 yılı hizmetiçi eğitim planı seçilmiştir. Bu çalışmanın verileri 2018 yılı Hizmetiçi eğitim planı belgesinden doküman analizi yöntemi ile toplanmıştır. Bu çalıșma 284 hizmetiçi eğitim planı içermektedir. Toplanan verilerin analizinde içerik analiz tekniği kullanılmıştır. Sonuç olarak eğitim kategorilerine göre kişisel, mesleki ve yönetim alanına yönelik hizmet içi eğitim faaliyetlerinin düzenlediği gözlenmiş̧ir. Öğretmenlere yönelik hizmetiçi eğitim programları öğretim şekillerine göre yüz yüze öğretim şekli ile yoğunlukla gerçekleştirildiği fakat katılımcı öğretmenlerinin sayısının düșük olduğu gözlemlenmiștir. Ayrıca öğretmenlere yönelik gerçekleştirilen hizmetiçi eğitim faaliyetlerinin eğitim bölgelerine göre dağılımının çeşitlendiği gözlemlenmiştir. Öğretmenlerin eğitim sahasında yaşanan değişimlere paralel kişisel, mesleki özelliklerinin yanında yönetim becerilerinin geliştirilmesi gerekir.

Anahtar sözcükler: Hizmetiçi eğitim, öğretmen eğitimi, hizmetiçi eğitim planı, hizmetiçi eğitim faaliyetleri

\begin{abstract}
The aim of the study is to investigate the inservice training plans for teachers run by the General Directorate of Teacher Training and Development in Turkey according to a variety of variables. These variables were participant profile, activity location, teaching form, education categories and topics related to inservice teacher training. This study was designed according to the case study method from the qualitative research methods. The population of the study was the 2001-2018 inservice training plans. This study used the easily accessible sample method from among targeted sampling methods to choose the 2018 inservice training plan. Data for the study were collected with document analysis of the 2018 inservice training plant document. This study included 284 inservice training plans. The data collected had the content analysis technique used. Finally, inservice training activities organized for personal, professional and managerial areas were observed according to training category. Inservice training programs for teachers were mainly completed with face-to-face teaching style; however low numbers of participatant teachers were observed. Additionally, inservice training activities for teachers were observed to have varied distribution according to educational region. In parallel with changes experienced by teachers in the training field, it is necessary to develop personal and professional traits along with management skills.
\end{abstract}

Keywords: In-service training, teacher training, in-service training plan, in-service training activities

\section{Cite this article as:}

Kaya, M. (2020). MEB öğretmen yetiştirme genel müdürlüğü'nün hizmet içi eğitim faaliyetleri: katılımcılar, eğitim durumları, eğitim konuları. Trakya Eğitim Dergisi, 10(1), 183-193.

\section{Introduction}

\section{Extended Abstract}

Changes in education science and education technology have brought retraining of teachers to the agenda. Variations in education science and education technology change the understanding of quality and competent teachers. With these changes, organizations and organs responsible for cultivating and developing teachers develop inservice education policies and plans according to the needs of working teachers and educational organizations.

\footnotetext{
${ }^{1}$ Dr. Öğr. Üyesi, Bayburt Üniversitesi, e-posta: metinkaya439@ gmail.com, ORCID: 0000-0002-8287-4929
} 
In Turkey, the unit responsible for ensuring cultivation and professional development of teachers is the General Directorate of Teacher Training and Development (GDTTD). With the aim of ensuring development of personal and professional characteristics of teachers, the GDTTD is responsible for preparing inservice training plans and programs.

Inservice training is a planned educational activity with the aim of gaining knowledge, skills, attitudes and behavior related to the duty of personnel employed in a workspace belonging to a private or legal entity (Öztürk, \& Sancak, 2007). Inservice training specific to the educational field is defined as development of human resources in a school system or more comprehensively within the educational system (Osamwonyi, 2016).

The aim of this study is to investigate the inservice teacher training plans in Turkey according to a variety of variables. This study is considered to be important in terms of observing and assessing inservice training plans. Additionally, it is thought to be important in terms of improving and developing inservice teacher training. In line with the aim of the study, answers to the following questions were sought.

\section{Method}

This study was designed according to the case study method from qualitative research methods. Case studies investigate a case or research object within its own context (Yıldırım \& Şimşek, 2006). Research objects investigated in case studies are customized and defined linked to space and time (Büyüköztürk, Çakmak, Ekgün, Karadeniz, \& Demirel, 2012).

The population of this research was inservice training plans from 2001 to 2018. According to the convenient (easily available) sampling method from the targeted sampling methods, the 2018 inservice training plan was chosen.

Data for this study were obtained with the document analysis method from the 2018 inservice training plan document.

The content analysis technique was used for analysis of collected data. Content analysis is the systematic summary of words or statements within a text in smaller content categories by coding according to certain principles and rules (Büyüköztürk et al., 2012).

\section{Results}

Among all inservice training activities, teacher professional training comprised 59.15\%, special quality training was $23.94 \%$, administrative and institutional training was $7.39 \%$ and activities for personal development comprised $9.51 \%$. Inservice training activities were observed to focus most on the east Marmara, northeast Anatolia, Mediterranean and İstanbul regions. Inservice education activities were observed to rarely be completed in west Black Sea, southeast Anatolia, and west Marmara regions. Of inservice training activities, $88.38 \%$ were in the form of face-to-face teaching, and $11.62 \%$ were in the form of remote (online) teaching.

For inservice training activities, participation rates were $85.21 \%$ teachers, $0.71 \%$ school administrators, $0.35 \%$ central organization staff, $5.28 \%$ officially selected and mixed rates of these groups for $8.45 \%$.

\section{Discussion and Conclusion}

The participant profile in this study observed teachers had high levels within all inservice activities for inservice training. Additionally, it was observed that inservice training activities were organized for other personnel in the school and education system. However, it is notable that school administrators, with a critical role in the education system, were observed to have low levels of courses and activities. It is necessary to ensure higher levels of participation of school administrators with critical roles in the school system where teachers work. This is because administration and education management are affected by globalization of science and development of information technologies. It is necessary that school administrators be trained, and their educational needs be met, in parallel with changes in management and education science. Additionally, it should be noted that in addition to present school administrators, teachers are each candidates to be school administrators. In this context, activities should be organized to gain knowledge and skills about school management and education management.

In this study, it was observed that the inservice training activities for teachers differed according to educational region. Inservice training activities were not held in the central-east Anatolian region and it was observed that inservice training activities were rarely held in west Black Sea, southeast Anatolia, and west Marmara regions. Özbek et al. (2018) observed that teachers chose to attend inservice training activities when they were held in regions close to where the teachers lived. It is necessary to ensure equal access to inservice training for teachers. With this reason, it is necessary to ensure distribution of 
inservice training courses and activities by noting the numbers of teachers distributed through the regions.

In the study, inservice training for teachers focused on the topic of gaining technologic skills in the area of personal development. Cemaloğlu et al. (2018) and Ceylan \& Özdemir (2016) observed that teachers required inservice training about the technological skills and use of education technologies in research. Programs about gaining technology skills should be standardized. Standardized inservice training programs should be distributed with local inservice training programs.

In this study, inservice training for teachers focused on the topic of project preparation in the administrative area, with administrative processes and activities less common. Demirel (2018) proposed that inservice training programs attended by school administrators reflected school management processes at positive level. Inservice training programs should be organized by noting management processes and actions about topics like planning, budget, communication, decision-making, organizational behavior and management and supervision.

This study observed that inservice training programs for teachers were completed mostly with the face-to-face teaching method; however, there were low numbers of participant teachers. On the other hand, it was observed that remote training ensured more access and participation of teachers in inservice training programs. Özavcı \& Çelikten (2017) and Aslan, Göksu \& Karaman (2018) emphasized that interactive completion of remote inservice training may increase the efficacy of remote inservice training programs. It is necessary to develop interactive inservice programs to increase teacher access to inservice training. Higgins \& Eden (2015) and Aykaç (2018) emphasized that inservice training programs based on practice and completed face-to-face with group working methods will develop the pedagogic knowledge and skills of teachers. It is necessary to design inservice training programs that are face-to-face and based on practice, using cooperative learning methods.

In conclusion, changes experienced in globalization, rapid changes in information technologies, education science and education technologies have made inservice training for teachers mandatory. In parallel with changes experienced by teachers in the education field, it is necessary to develop personal and professional traits along with administrative skills.

\section{GİRIŞ}

Türkiye'de hizmetiçi öğretmen eğitimi 1960 yılında MEB'e bağlı Öğretmeni İşbaşında Yetiştirme Bürosu ile başlamıştır. Sözü edilen büro 1975 yılında Hizmet İçi Daire Başkanlığına dönüştürülmüştür (Özcan ve Bakioğlu, 2010). 2011 yılında Milli Eğitim Bakanlığının Teşkilat ve Görevleri Hakkında Kanun Hükmünde Kararname ile Hizmetiçi Eğitim Dairesi Başkanlığ kaldırılmış ve yetkileri Öğretmen Yetiştirme ve Geliştirme Genel Müdürlüğü (ÖYGM)'ne devredilmiştir (ÖYGM, 2019a). 2011 y1l itibari ile ÖYGM öğretmenlere yönelik hizmeti içi eğitim faaliyetlerini yürütmektedir.

Türkiye'de öğretmenlerin yetiştirilmesi ve mesleki gelişimlerinin sağlanmasından sorumlu organ/birim ÖYGM' dür. ÖYGM öğretmenlerin kişisel ve mesleki niteliklerinin gelişimlerini sağlamak amacıyla hizmetiçi eğitim planı ve programları hazırlamakla görevlidir (Cumhurbaşkanlığı Teşkilatı Hakkında Cumhurbaşkanlığı Kararnamesi, 2018, s.144). ÖYGM hizmetiçi eğitim programlarının performansını artırmak amacıyla hizmetiçi eğitim "standart eğitim (etkinlik)" programı hazırlamıştır. ÖYGM'nin hazırladığı standart eğitim programı kişisel gelişim, öğretmen eğitimi, yönetim ve kurumsal eğitimler, özel nitelikli eğitim olmak üzere dört ana alandan oluşmaktadır (ÖYGM, 2019b). Standart eğitim programları aracılığı ile hizmetiçi öğretmen eğitimde belirli bir düzeyde kalite oluşturmaya çalışmaktadır. Böylelikle hizmetiçi eğitim faaliyetlerin verimliğini ve etkinliğini artırmak amaçlanmaktadır.

Hizmetiçi eğitim; özel ya da tüzel kişiliğe ait işyerlerinde çalışan personelin görevi ile ilgili bilgi, beceri, tutum ve davranış kazandırmak amacıyla yapılan planlı eğitim faaliyetleridir (Öztürk, \& Sancak, 2007). Eğitim alanına özgü olarak hizmetiçi eğitim; okul sistemi ya da kapsamlı bir ifade ile eğitim sistemi içerisindeki insangücü kaynağının geliştirilmesi olarak tanımlanmaktadır (Osamwonyi, 2016). Hizmetiçi öğretmen eğitimi ise önceden belirlenmiş eğitim ve öğretim amaç ve hedeflerini öğrencilere kazandırma sürecinde öğretmenlik mesleğinin için gerek duyulan bilgi, beceri, tutum ve davranışlarının kazandırılmasına ilişkin süreçlerinin tümü olarak tanımlanmaktadır (Aslan, Göksu,\& Karaman, 2018). Öğretmenlerin kişisel ve mesleki gelişimlerinin sağlamak amacıyla hizmetiçi eğitim plan ve 
programları birçok hedefi gerçekleştirmek üzere düzenlenmektedir. Hizmetiçi öğretmen eğitimin hedefleri aşağıdaki gibidir.

Yeni göreve başlayan öğretmenlerin kuruma uyumlarını sağlamak

Eğitim kurumlarının amaç, ilke, değerlerine katkı sağlayacak bilgi, beceri ve tutum kazandırmak

Öğretmenlerin etkinliğini, verimliliğini ve doyumunu artırmak,

Eğitim kurumlarının performansını ve öğretmenlerin görev performansını artırmak

Değişen ve gelişen eğitim yaklaşımlarına ilişkin kişisel özellikler kazandırmak

Değişen ve gelişen eğitim yaklaşımlarına ilişki mesleki bilgi, beceri, tutum ve davranış kazandırmak,

Öğretmenlerin yatay ve dikey geçişlerine imkân sağlayacak tamamlayıcı eğitimler sunmak

Öğretmenlerin kariyer gelişimi için deneyim ve tecrübelerini zenginleştirmek

Mesleki sorunları çözme becerileri kazandırmak

İş kazalarını ve meslek hastalıklarını önlemek, iş sağlığı ve iş güvenliğini sağlamaktır (Önen,

Mertoğlu, Saka, \& Gürdal, 2009; Özbek, Susam, Onat, \& Özbek,2018; Öztürk\& Sancak, 2007).

Literatür incelendiğinde öğretmelere yönelik hizmetiçi eğitim teori ve modelleri (Higgins, \& Eden, 2015; Köksal, \& Southerland, 2018; Öztürk, 2019; Sakkoulis, Asimaki, \& Vergidis, 2018; Şahin \& Türkoğlu, 2017) eğitim kademelerine ve öğretmen branşlarına göre hizmetiçi programlarının değerlendirilmesi (Uysal, 2012; Yılmaz \& Kocasaraç, 2010), öğretmenlerin hizmetiçi eğitim ihtiyaçları (Cemaloğlu \& diğer, 2018; Gökdere \& Çepni, 2004; Mede \& Iş1, 2016; Ulla, \& Winitkun, 2018), öğretmenlerin hizmetiçi eğitim faaliyetlerine ilişkin tutum ve görüşleri (Can \& Kösel, 2015; Karasolak, Tanrıseven \& Konokman, 2012), hizmetiçi eğitimin etkinliği ve yeterliği (Ntuli, 2018; Önen, Mertoğlu, Saka, \& Gürdal, 2009; Özbek, Susam, Onat, \& Özbek,2018; Özcan ve Bakioğlu, 2010; Uzunöz, 2012 ), öğretmenlerin hizmetiçi eğitime katılımı ve beklentileri (Ceylan, \& Özdemir, 2016; Öztürk, \& Öztürk, 2019;), uzaktan hizmetiçi eğitimin sorunları (Özavcı, \& Çelikten, 2017) ve başarısı (Aslan, Göksu, \& Karaman, 2018) araştırmacılar tarafindan incelenmiştir. Bunların yanında okul yöneticilerinin hizmetiçi eğitim faaliyetlerine yönelik görüşleri incelenmiştir( Demirel, 2018). Öte yandan öğretmenlere yönelik hizmetiçi eğitim planlarının incelendiği araştırmalara rastlanmamıştır.

Bu çalışmanın amacı Türkiye'nin hizmetiçi öğretmen eğitimi planlarının katılımcı profili,eğitim durumları ve eğitim konularına göre incelemektir. Bu çalışma hizmetiçi eğitim planlarının hizmetiçi eğitim konuları, katılımcı profillerine ve eğitim durumlarına göre izlenmesi ve değerlendirilmesi açısından önemli olduğu düşünülmektedir. Böylelikle hizmet içi eğitim programlarına katılan katılımcıların çeşitlenmesi, hizmetiçi programların eğitim bölgelerine göre daha adil dağılımının sağlanması ve öğretmenlerin, okul yöneticilerinin hizmetiçi eğitim faaliyetlerine etkin ve kolay erişimlerinin sağlanması bakımından önemli olduğu düşünülmektedir. Ayrıca hizmetiçi öğretmen eğitimin iyileştirilmesi ve geliştirilmesi açısından önemli olduğu düşünülmektedir. Bu araştırmanın amacı doğrultusunda aşağıdaki soruları cevap aranmıştır.

Hizmetiçi öğretmen eğitimi programlarının eğitim kategorileri ve konularına göre dağılımı nasıldır? Hizmetiçi öğretmen eğitimi programlarını katılan katılımcılarının profiline göre dağılımı nasıldır?

Hizmetiçi öğretmen eğitimi programlarının faaliyet yerlerine göre dağılımı nasıldır?

Hizmetiçi öğretmen eğitimi programlarının öğretim şekillerine göre dağılımı nasıldır?

\section{YÖNTEM}

$\mathrm{Bu}$ çalışma nitel araştırma yöntemlerinden durum çalışması yöntemine göre desenlenmiştir. Durum çalışmalarında bir olgu ya da bir araştırma nesnesi kendi bağlamı içerisinde incelenir (Yıldırım \& Şimşek, 2006). Durum çalışmalarında incelenen araştırma nesneleri mekân ve zamana bağlı olarak özelleştirilir ve tanımlanır (Büyüköztürk, Çakmak, Ekgün, Karadeniz \& Demirel, 2012). Bu çalışmada öğretmen eğitimi hizmetiçi planlarının mevcut durumu analiz edilmek amaçlandığından durum çalışması yöntemi tercih edilmiştir.

ÖYGM, 2001 yılından itibaren hizmetiçi eğitim planlarını yayımlamaktadır. Hizmetiçi eğitim planları MEB'nın öğretmen eğitimi politikalarını yansıtan önemli bir belgedir. Hizmetiçi eğitim planları; hizmetiçi eğitim konuları ve içeriği, katılımcıların seçimi, hizmetiçi eğitim faaliyetinin gerçekleştirileceği eğitim bölgesi, hizmetiçi eğitimde kullanılan öğretim yöntemlerini içermesi bakımından mevcut durumu yansıtan bir belgedir. Bu çalışmada 2018 yılı 
hizmetiçi eğitim planı seçilmiştir. 2018 yılı Hizmetiçi eğitim planı günümüze en yakın eğitim planı olması sebebi ile mevcut durumu yansıtacağı düşünülmektedir.

\section{Veri toplama}

$\mathrm{Bu}$ çalışmanın verilerine 2018 yılı Hizmetiçi eğitim planı belgesinden doküman analizi yöntemi ile incelenmiştir. Doküman analiz yöntemi yazılı materyalleri incelemek için sık kullanılan bir veri toplama yöntemidir (Yıldırım \& Şimşek, 2006). Doküman analizi yöntemi kapsamında kurumsal raporlar, kitaplar, dergiler, arşiv dosyaları, görsel ve sesli kayıtlardan veri toplanabilmektedir (Karataş, 2015) 2018 yılı hizmetiçi eğitim planına ÖYGM ait web sitesinden (http://oygm.meb.gov.tr) erişilmiştir. 2018 y1lı hizmetiçi eğitim planı toplam 436 faaliyet içermektedir. Bu faaliyetlerden 152'si çeşitli nedenlerle iptal edilmiştir. Buna göre bu çalışma toplam 284 hizmetiçi eğitim faaliyetini kapsamaktadır.

\section{Veri analizi}

Toplanan verilerin analizinde içerik analiz tekniği kullanılmıştır. İçerik analizi belirli ilke ve kurallara göre yapılan kodlamalarla bir metninin içerisindeki sözcük veya ifadelerin daha küçük içerikteki kategorilerle sistematik bir biçimde özetlenmesidir (Büyüköztürk \& diğ., 2012). Verilerin analizinde içerik analizine uygun kod ve kategoriler belirlenmiştir. Verilerin sunumda kod ve kategorilere ilişkin frekans ve yüzdelik oranlar kullanılmıştır.

ÖYGM hizmetiçi eğitim faaliyetlerinde standart sağlanması amacıyla standart eğitim kategorileri, alanları ve konularını geliştirmiştir. Bu çalışmanın kodlamalarında sözü edilen ÖYGM'nin hizmetiçi eğitim standart kategorileri, alanları ve konularına göre hizmet içi eğitim programları kodlanmış, daha sonra kodlar, kategoriler altında birleştirilmiştir. Kodlama işlemi ilk aşamada araştırmacı ve eğitim yönetimi alanında bir uzmanla birlikte yapılmıştır. Bu aşamada 2018 hizmetiçi eğitim planının ilk 20 etkinlik birlikte kodlanmıştır. Kodlama işlemi güvenirliği için uzlaşı sağlanmaya çalışılmıştır. Bu aşamadan sonra kodlama işlemleri araştırmacı tarafından gerçekleştirilmiştir. Araştırmanın geçerliliği ve güvenirliği bağlımda kategoriler arasında, kategoriler içinde ve kodlar arasında sürekli karşıllaştırma yapılarak kodlamış ve kategorilere yerleştirilmiştir. Tutarsız olduğu düşünülen kodlamalar gözden geçirilmiş ve buna göre düzenlenmeler tekrar yapılmıştır. Kodlar arası ve kategoriler içi tutarsızlık durumlarında eğitim yönetimi alanında iki uzman görüşüne başvurularak karar verilmiştir.

Hizmet içi eğitim planındaki faaliyet adı ve ilgili faaliyet programının amacına incelenmiş ve buna göre hizmetiçi öğretmen eğitimi konusu kodlanmıştır. Örneğin 'AB Proje Hazırlama Teknikleri Kurs" programı konu olarak "proje" olarak kodlanmış ve "yönetim ve kurumsal eğitim kategorisi" altında değerlendirilmiş̧ir. Hizmetiçi eğitim planları eğitim kategorileri ve konuları, öğretim bicimi, katılımcı profili, eğitim bölgelerine göre kodlanmıştır.

\section{BULGULAR ve YORUM}

Bu bölümde araştırma kapsamında elde edilen bulgular, araştırma problemlerine göre sirasıyla sunulmuş ve yorumlanmıştır

Tablo 1. Hizmet içi eğitim programlarının eğitim kategori ve konularına göre dağglımı

\begin{tabular}{|c|c|c|c|}
\hline Kate. & Konular & $\mathrm{f}$ & $\%$ \\
\hline \multirow{4}{*}{ 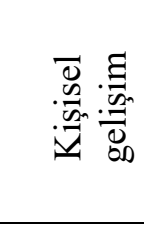 } & Teknoloji kullanım becerileri & 17 & 5,99 \\
\hline & Yetişkin eğitimi & 9 & 3,17 \\
\hline & Yaşam becerileri & 1 & 0,35 \\
\hline & Ara toplam & 27 & 9,51 \\
\hline \multirow{2}{*}{ : } & Liderlik & 2 & 0,7 \\
\hline & Personel eğitimleri & 1 & 0,35 \\
\hline
\end{tabular}




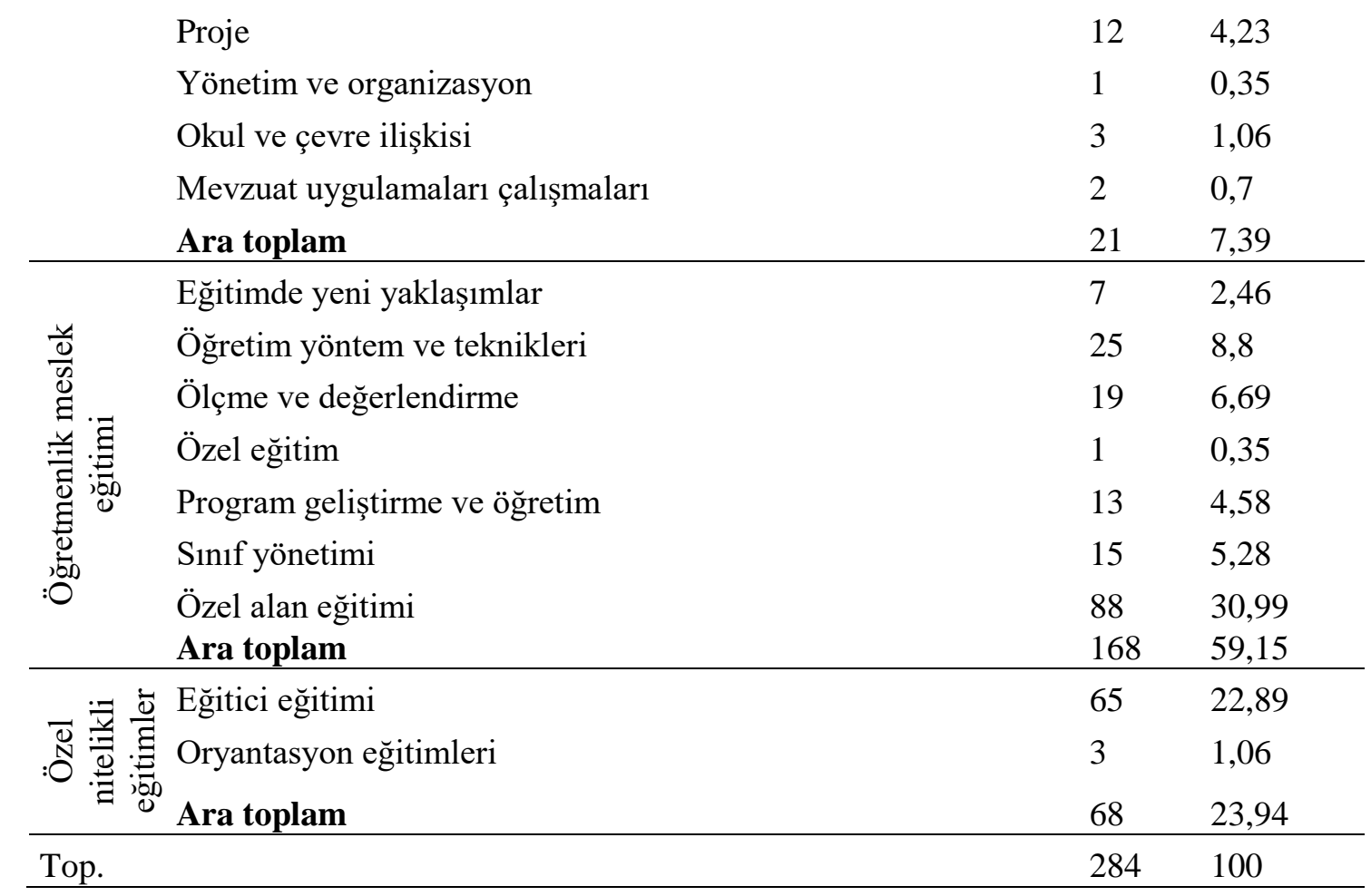

Tablo 1'de hizmetiçi eğitim programlarının eğitim kategorileri ve konularına göre frekans ve yüzde dağılımı sunulmuştur. Tablo 1 incelendiğinde öğretmenlik meslek eğitimi kategorisinde düzenlenen programların tüm faaliyetler içinde payının yüzde $\% 59,15$; özel nitelikli eğitimlerin $\%$ 23,94; yönetsel ve kurumsal eğitimlerin \%7,39; kişisel gelişim yönelik faaliyetlerin payının \%9,51 olduğu gözlenmiştir. Hizmetiçi eğitim kategorileri konularına göre incelendiğinde kişisel gelişim kategorisinde teknolojik becerileri konusunda sık; yaşama becerileri ve yetişkin eğitimi konularına yönelik faaliyetlerin nispeten daha seyrek düzenlendiği gözlenmiştir. Yönetimsel ve kurumsal eğitim kategorisinde proje hazırlama konusunun daha sık liderlik, yönetim ve organizasyon, mevzuat uygulamaları ve personel eğitimi konularına yönelik faaliyetlerin seyret düzenlendiği gözlenmiştir. Özel nitelikli eğitimler kategorisinde sıklıkla eğiticilerin eğitimine yönelik faaliyetler düzenlenirken ortanyansyon ile ilgili kursların oldukça seyrek olduğu gözlenmiştir. Oryantasyon eğitimlerinin seyrek olmasının sebebi MEB merkez yönetimin yeni başlayan öğretmenler için oryantasyon etkinliklerini taşra teşkilatları bünyesinde yürütülmesinden kaynaklanıyor olabilir. Öğretmenlerin mesleki eğitimler kategorisinde özel alan eğitimlerinin payının \%30,99 düzeyinde olması dikkat çekicidir. Bu durum mesleki ve teknik eğitim kurumlarında meslek öğretmelerinin özel alan eğitimiyle (alan bilgisi) ilişkili olduğu söylenebilir. Sözü edilen oranın tamamı mesleki ve teknik öğretmenlerin alan bilgisi ile ilgilidir. Öte yandan öğretmenlik meslek eğitimi kategorisinde ölçme ve değerlendirme, öğretim yöntem ve teknikleri, sınıf yönetimi ve program geliștirme ve öğretimi konuları özel alan eğitim (alan bilgisi) konusuna göre nispeten daha seyrek olarak faaliyetler düzenlendiği gözlenmiştir. Ayrıca özel eğitim alanında düzenlenen kurs oranın oldukça düşük bir düzeyde olması dikkat çekicidir. Öte yandan bir ögretmenlik yeterlilik konusu olan rehberlik konusuna ilişkin faaliyetlere rastlanmamıştır.

Tablo 2. Hizmet içi eğitim faaliyetlerinin eğitim bölgelerine göre dağılımı

\begin{tabular}{lll}
\hline Faaliyet Yeri & f & \% \\
\hline İstanbul & 28 & 11,16 \\
Doğu Marmara & 66 & 26,29 \\
Bat1 Marmara & 3 & 1,2 \\
Batı Anadolu & 25 & 9,96 \\
Orta Anadolu & 14 & 5,58
\end{tabular}


Ege

Akdeniz

Bat1 Karadeniz

Doğu Karadeniz

Kuzeydoğu Anadolu

Güneydoğu Anadolu

Ortadoğu Anadolu

Toplam

24 farklı ilde düzenlenen hizmetiçi eğitim faaliyetleri eğitim bölgelerine göre gruplandırılmıştır. Tablo 2'de hizmetiçi eğitim faaliyetlerinin gerçekleştirildiği eğitim bölgelerine göre frekans ve yüzde dağılımı sunulmuştur. Tablo 2 incelendiğinde hizmetiçi eğitim faaliyetlerinin en s1k Doğu Marmara, Kuzeydoğu Anadolu, Akdeniz, İstanbul bölgesinde yoğunlaştığı gözlenmiştir. Hizmetiçi eğitim faaliyetlerinin nadir olarak Batı Karadeniz, Güneydoğu Anadolu, Batı Marmara bölgesinde gerçekleştirildiği gözlenmiştir. Ayrıca Ortadoğu Anadolu bölgesinde ise öğretmenlere yönelik hizmetiçi eğitim faaliyeti düzenlenmediği gözlenmiştir. Bu durum Orta Anadolu bölgesinde hizmetiçi eğitim merkezinin olmamasından kaynaklanıyor olabilir.

Tablo 3. Hizmet içi eğitim öğretim şekli

\begin{tabular}{lll}
\hline Öğretim şekli & $\mathbf{f}$ & \% \\
\hline Uzaktan eğitim $(\mathrm{N}=43000)$ & 33 & 11,62 \\
Yüz yüze $(\mathrm{N}=16413)$ & 251 & 88,38 \\
& 284 & 100 \\
\hline
\end{tabular}

Tablo 3'de hizmetiçi eğitim faaliyetlerinin öğretim biçimine ilişkin frekans ve yüzde dağılımı sunulmuştur. Tablo 3 incelendiğinde hizmetiçi eğitim faaliyetlerinin $\% 88,38$ yüz yüze öğretim biçiminde, \%11,62'sinin ise uzaktan eğitim (çevrimiçi) öğretim biçimi ile gerçekleştirildiği gözlenmiştir. 43000 öğretmen ve diğer personelinin hizmetiçi uzaktan eğitime katılması hedeflenmiştir. Öte yandan 16413 öğretmen ve diğer personelin yüz yüze hizmetiçi eğitim faaliyetlerine katılması hedeflenmiştir.

Tablo 4. Hizmet içi eğitime alınan katılımcı profili dağılımı

\begin{tabular}{lll}
\hline Katılımı profili & f & \% \\
\hline Öğretmen & 242 & 85,21 \\
Okul yöneticisi & 2 & 0,71 \\
Merkez teşkilat personeli & 1 & 0,35 \\
Karma (öğr,okul yönetici, merkez teşkilat personeli) & 24 & 8,45 \\
Resen seçilen & 15 & 5,28 \\
Toplam & 284 & 100 \\
\hline
\end{tabular}

Tablo 4'de hizmetiçi eğitim alan katılımcıların profiline ilişkin frekans ve yüzde dağılımı sunulmuştur. Tablo 4 incelendiğinde hizmetiçi eğitim faaliyetlerine öğretmenlerin katılımı $\% 85,21$, okul yöneticilerinin katılım oran $1 \% 0,71$, merkez teşkilat personelinin katılım oranı $\% 0.35$, resen seçilenlerin oran $\% 5,28$, sözü edilen gruplara göre karma katılımcıların oranı $\% 8,45$ düzeyinde olduğu gözlenmiştir. Katılımcı oranları dikkate alınıldığında eğitim sistemi içerisinde önemli olan okul yöneticilerinin katılımının dikkat çekici düzeyde düşük olduğu gözlenmiştir. 


\section{TARTIŞMA ve SONUÇ}

Bu çalışmada Türkiye'de ÖYGM'in yürüttüğü öğretmenlere yönelik hizmetiçi eğitim planları çeşitli değiş̧kenlere göre incelemiştir. Bu değişkenler hizmetiçi eğitimi ilişkin katılımc1 profili, faaliyet yeri, öğretim biçimi, eğitim kategorileri ve konularıdır.

$\mathrm{Bu}$ çalışmada katılımcı profiline hizmetiçi eğitime öğretmenlerinin katılımı tüm hizmet içi faaliyetleri içerisinde oldukça yüksek düzeyde olduğu gözlenmiştir. Ayrıca okul ve eğitim sistemi içerisindeki diğer personellere yönelik hizmetiçi eğitim faaliyetlerinin düzenlendiği gözlemlenmiştir. Fakat eğitim sistemi içerisinde kritik rolü olan okul yöneticilerine yönelik kurs ve etkinliklerin dikkat çekici düzeyde düşük olduğu gözlemlenmiştir.

Öğretmenlerin görev olarak yürüttükleri ve okul sisteminde kritik rolleri olan okul yöneticilerinin daha yüksek düzeyde katılımlarının sağlanması gerekir. Çünkü yönetim ve eğitim yönetimi bilimi küreselleşme ve bilgi teknolojilerinin gelişimden etkilenmektedir. Yönetim ve eğitim biliminde yaşanan değişimlere paralel olarak okul yöneticilerinin de yetiştirilmesi ve eğitim ihtiyaçlarının karşılanması gerekir. Ayrıca sadece mevcut okul yöneticilerinin yanında öğretmenlerin birer okul yönetici adayı oldukları dikkate alınmalıdır. Bu bağlam da öğretmelere okul yönetimi ve eğitim yönetimine ilişkin bilgi ve beceri kazandıracak faaliyetler düzenlenmelidir. Başka bir ifade ile Türkiye'de okul yöneticiliği bir meslek olarak tanımlanmamaktadır. Bu durumda dikkate alındığında öğretmenlerin birer yönetici adayı olduğu ve hizmetiçi eğitim programları alternatif okul yönetici yetiştirme programı olarak değerlendirilmelidir. Hizmetiçi eğitim programlarına katılımcı personel (öğretmen, yönetici, uzman ve diğer) profilleri izlenmelidir. MEB bünyesinde çalışan eğitim, öğretimden ve yönetim ve diğer görevlerden sorumlu personelin gelişimine yönelik politikalar geliştirilmesine yardımcı olabilir.

Bu çalışmada öğretmenlere yönelik gerçekleştirilen hizmetiçi eğitim faaliyetlerinin eğitim bölgelerine göre dağılımının çeşitlendiği gözlemlenmiştir. Ortadoğu Anadolu bölgesinde hizmetiçi eğitim faaliyetinin gerçekleştirilmediği ve Batı Karadeniz, Güneydoğu Anadolu, Batı Marmara bölgelerinde ise nadir düzeyde hizmetiçi eğitim faaliyetleri gerçekleştirildiği gözlenmiştir. Ö̈zbek \& diğ. (2018) hizmetiçi eğitimin faaliyetleri öğretmenlerin yaşadıkları yere yakın olan bölgelerde gerçekleştirilmesi halinde öğretmenlerin tercih ettiklerini gözlemlemişlerdir.

Öğretmenlerin hizmetiçi eğitime eşit erişimlerinin sağlanması gereklidir. Bu sebeple öğretmen sayılarının bölgelere dağılımı dikkate alınarak hizmetiçi eğitim etkinliklerinin dağılımının düzenlenmesi gereklidir. hizmetiçi eğitime öğretmenlerin erişimi etkin bir öğretim için önemlidir. hizmetiçi eğitim programları ile öğretmenlerin mesleki özellikleri gelişmektedir. Ögretmenlerin mesleki gelişimi öğretmenlerin nitelikleri artırmakta bu artış eğitim ortamına ve öğrenci davranışları olumlu yönde yansımaktadır. Böylelikle öğrenciler daha nitelikli öğretmelere erişimi sağlanmış olur.

$\mathrm{Bu}$ çalışmada öğretmenlere yönelik gerçekleştirilen hizmetiçi eğitimlerin kişisel gelişim alanında teknolojik beceri kazandırma konusuna yoğunlaştığı gözlemlenmiştir. Cemaloğlu \& diğer, (2018) ve Ceylan \& Özdemir (2016) araştırmalarında öğretmenlerin teknolojik beceriler ve eğitim teknolojileri kullanma konusunda hizmet eğitimi ihtiyaç duyduklarını gözlemlemişleridir. Teknoloji becerileri kazandırmaya yönelik programlar standartlaştırılmalıdır. Standartlaştırılmış hizmetiçi eğitim programları mahalli hizmetiçi eğitim programları ile yaygınlaştırılması sağlanmalıdır. Öte yandan öğretmenlerin yaşam becerilerine ilişkin hizmetiçi eğitim programlarının seyrek olduğu gözlenmiştir. Yaşam becerileri düşük olan öğretmenlerin eğitimin bir genel amacı olan öğrencileri yaşama hazırlama amacını etkin gerçekleştirebileceği söylenemez. Bu açıdan bakıldığında öğretmenlerin yaşam becerilerinin geliştirmek için hizmetiçi eğitim faaliyetlerinin artırılması gerekir. Öğretmen davranışları ve tutumları öğrenci davranışları için bir modeldir. Bu bakış açısından yola çıkarak öğretmenlerin yaşam becerilerinin geliştirilmesi öğrencilerin davranışlarına ve tutumlarına olumlu yönde yansiyabilir. 
$\mathrm{Bu}$ çalışmada öğretmenlere yönelik gerçekleştirilen hizmetiçi eğitimlerin mesleki gelişim alanında öğretmenlik meslek yeterlilikleri olan ölçme değerlendirme, öğretim yöntem ve teknikleri, sınıf yönetimi, program geliştirme ve öğretimi konularına yönelik kurs ve etkinliklerin düzenledikleri gözlemiştir. Mede \& Işı, (2016) sınıf yönetimi, sınıf ortamının düzenlemesi, öğrenci merkezli öğretim yöntemleri, materyal geliştirme ve eğitim teknolojileri kullanma, program geliştirme konularında öğretmenlerin hizmetiçi eğitime ihtiyaç duyduklarını gözlemlemiştirler. Ulla \& Winitkun, (2018) ise ögretim strateji, yöntem ve tekniklerine konularında öğretmenlerin hizmetiçi eğitime ihtiyaç duyduklarını gözlemlemiştirler. Sözü edilen araştırmalar ile bu çalışmanın bulguları örtüşmektedir. $\mathrm{Bu}$ çalışmanın bulguları 1şığında öğretmenlerin rehberlik becerilerine yönelik kursların düzenlenmemesi dikkat çekicidir. Ayrıca özel eğitime yönelik kurs ve etkinliklerin yetersiz bir düzeyde düzlendiği gözlenmiştir. Gökdere \& Çepni, (2004) ise üstün yetenekli öğrencilerin eğitim ve öğretimine yönelik öğretmenlerin hizmetiçi eğitime ihtiyaçlarını vurgulamaktadır.

Özel eğitim ihtiyacı olan öğrenci grupları (işitme engelli, görme engelli, kaynaştırma öğrencileri ve diğer.) yönelik öğretmenlerin özel eğitim bilgi, becerilerini geliştirilmesine yönelik hizmet içi eğitim programları geliştirilmelidir. Ayrıca öğretmenlerin rehberlik ve danışma becerilerini geliştirici hizmetiçi programlarının düzenlenmesi gereklidir. Öğretmenlerin rehberlik becerilerinin geliştirilmesi öğrencilerinin gelişimine olumlu katkı sağlayabilir ve gelişimlerini destekleyebilir.

Bu çalışmada öğretmenlere yönelik gerçekleştirilen hizmetiçi eğitimlerin yönetim alanında proje hazırlama konusunun yoğun olduğu diğer yönetim süreç ve etkinliklerinin daha seyrek olduğu gözlenmiştir. Demirel (2018) okul yöneticilerinin katıldıkları hizmetiçi eğitimi programlarının okul yönetim süreçlerine olumlu düzeyde yansıdığını öne çıkarmaktadır.

Yönetim süreç ve eylemleri dikkate alınarak planlama, bütçe, iletişim, karar verme, örgütsel davranışların ve yönetimi, denetleme konularında hizmet içi eğitim programları düzenlenmelidir. Hazırlanan hizmet içi eğitim programları standartlaştırılmalı ve mahalli hizmetiçi eğitim programlarında uygulanması için üst düzey eğitim yöneticileri teşvik edilmelidir. standartlaştırılmış eğitim programlarının taşra teşkilatlarında uygulanması ögretmenlerin mesleki, yönetsel ve kişisel gelişimine katkı sağlayabilir.

Bu çalışmada öğretmenlere yönelik gerçekleştirilen özel nitelikli eğitimler içerisinde en sık eğiticilerin eğitimine ilişkin faaliyetlerin gerçekleştirildiği gözlemlenmiştir. O'Dwyer \& Atlı (2015) araştırmalarında eğiticilerin eğitiminin hizmetiçi eğitimde kritik bir rolü olduğunu ifade etmektedirler. Eğiticilerin eğitimi uygulaması ile merkezin öngördüğü değişimlerin taşra teşkilatlarına aktarımı sağlanmaktadır. Hizmetiçi eğitim yaygınlaştırılması açısından eğiticilerin eğitimi bir araç olarak değerlendirilmelidir. Eğiticilerin eğitimine ilişkin kursların artırılması gerekir. Böylelikle hizmetiçi eğitim etkinlikleri taşrada çalışan öğretmenlere uzmanlar aracılığı ile erişimi etkin bir şekilde sağlanmış olur.

$\mathrm{Bu}$ çalışmada öğretmenlere yönelik hizmetiçi eğitim programlarının yüz yüze öğretim şekli ile yoğunlukla gerçekleştirildiği fakat katılımcı öğretmenlerinin sayısının düşük olduğu gözlemlenmiştir. Öte yandan uzaktan eğitim şekli ile daha çok öğretmenin hizmetiçi eğitimi programlarına erişimi ve katılımın sağlandığı gözlenmiştir. Özavcı \& Çelikten (2017) ve Aslan, Göksu \& Karaman (2018) araştırmalarında uzaktan hizmetiçi eğitimin interaktif gerçekleştirilmesinin uzaktan hizmetiçi eğitimi programlarının etkinliğini yükseltebileceğini vurgulamaktadırlar. Öğretmenlerin hizmetiçi eğitime erişimlerinin yükseltilmesi için interaktif hizmetiçi programlarının geliştirilmesi gereklidir. Higgins \& Eden (2015) ve Aykaç (2018) ise hizmetiçi eğitim programlarının pratiğe dayalı ve grup çalışma yöntemleri ile yüz yüze gerçekleştirilmesinin öğretmenlerin pedagojik bilgi ve becerilerinin gelişebileceğini vurgulamaktadir.

Hizmetiçi eğitim programların yüz yüze, pratiğe dayalı ve işbirlikli öğrenme yöntemlerine desenlemesi gereklidir. Böylelikle hizmetiçi öğretmen eğitimin etkinliği artırılabilir.

$\mathrm{Bu}$ çalışmada öğretmenlere yönelik kişisel, mesleki ve yönetim alanına yönelik hizmetiçi eğitim faaliyetlerinin düzenlediği gözlenmiştir. Yolcu \& Kartal (2017) araştırmalarında öğretmenlere yönelik genel kültür, mesleki gelişim ve spesifik konularda hizmetiçi eğitim faaliyetleri düzenlendiğini gözlemişleridir. Bu çalışmanın bulguları ile sözü edilen çalışmanın bulguları örtüşmektedir. Kocatürk (2016) hizmetiçi eğitim programlarının kamuda çalışanların 
performansına pozitif yönde etkilediğini gözlemlemiştir. Gümüşoğlu (2016) ise hizmetiçi eğitim programlarının öğretmenlerin sınıf içi performanslarına etkisini vurgulamaktadır.

Öğretmenlerin mesleki gelişimlerini yanında kişisel özelliklerinin gelişimi ve yönetim becerilerinin geliştirilmesine önem verilmelidir. ÖYGM hizmetiçi eğitim programlarının kalitesinin artırmak için geliştirdiği standart eğitim programları yaşanan değişimler, öğretmenlerin ve okulların ihtiyacına göre güncelleştirilmeli ve geliştirilmedir. Öğretmenlerin hizmetiçi eğitim ihtiyaçları ve beklentileri belirlenmelidir. Öğretmenlerin hizmetiçi eğitim ihtiyaçları ve beklentilerini belirlemeye yönelik araştırmalar yapılması gerekir. Ayrıca bu çalışma merkezi yönetimin hizmetiçi eğitim programları incelenmiştir bunun yanında mahalli (taşra teşkilatlarının) hizmetiçi eğitim programlarının incelenmesi gereklidir.

\section{KAYNAKLAR}

Aslan, A., Göksu, İ., Karaman, S. (2018). Uyarlanabilir uzaktan hizmetiçi eğitimin başarı ve eğitimin tamamlama süresine etkisi ile öğretmen görüşleri. Buca Eğitim Fakültesi Dergisi, (45), 103-115.

Aykaç, N. (2018). Investigation of the in-service teacher training programs in the united states and recommendations for turkey: the case of kent education excellence partnership (KEEP). Journal of Education and Future, (14), 181-197.

Büyüköztürk, Ş., Kılıç Çakmak, E., Akgün, Ö. E., \& Karadeniz, Ş., Demirel F. (2012). Bilimsel araştırma yöntemler. Ankara: Pegem Akademi Yayınları.

Can N., \& Kösel, A. (2015). İlkokul ve ortaokul yöneticilerinin hizmetiçi eğitim ve geliştirme kavramlarına ilişkin görüşleri ve beklentileri. KSÜ Sosyal Bilimler Dergisi 12(2), 85-118.

Cemaloğlu, N., Kukul, V., Üstündağ, M. T., Güneş, E., \& Arslangilay, A., S. (2018). Eğiticilerin hizmet içi eğitim ihtiyaçlarının belirlenmesi: bilecik ili örneği. Electronic Turkish Studies, 13(11), 399420.

Ceylan, M., \& Özdemir, S. (2016). Türkiye ve İngiltere'deki öğretmenlerin sürekli mesleki gelişime ilişkin görüşlerinin ve katılım durumlarının incelenmesi. Kırıkkale Üniversitesi Sosyal Bilimler Dergisi, 6(1), 397-417.

Cumhurbaşkanlığı Teşkilatı Hakkında Cumhurbaşkanlığı Kararnamesi (2018, 10 Temmuz). Resmi $\begin{array}{llll}\text { Gazete. } & \text { (Say1: } & \text { 30474). } & \text { 17.04.2019 }\end{array}$ http://www.mevzuat.gov.tr/MevzuatMetin/19.5.1.pdf. adresinden alınmıştır.

Demirel, I., N. (2018). The Opinions of administrators about in-service training related to the administration and investigation. International Journal of Higher Education, 7(2), 76-83.

Gökdere, M., \& Çepni, S. (2004). Üstün yetenekli öğrencilerin fen öğretmenlerinin hizmetiçi ihtiyaçlarının değerlendirilmesine yönelik bir çalışma bilim sanat merkezi örneklemi. Gazi Üniversitesi Gazi Eğitim Fakültesi Dergisi, 24(2), 1-14.

Gümüşoğlu, D. (2016). İngilizce öğretmenlerinin hizmetiçi eğitim süreçleri ve hizmetiçi eğitim etkinliklerinin sınıfiçi performanslarına etkisine ilişsin algıları (yayınlanmamıs yükseklisans tezi). Yeditepe Üniversitesi, İstanbul.

Higgins, J., \& Eden, R. (2015). Practice-based inservice teacher education: generating local theory about the pedagogy of group work. Mathematics Teacher Education and Development, 17(2), 84-97.

Karasolak, K., Tanrıseven, I., \& Konokman, G., Y. (2012). Öğretmenlerin hizmetiçi eğitim etkinliklerine ilişkin tutumlarinin belirlenmesi. Kastamonu Eğitim Dergisi, 21(3), 997-1010.

Karataş, Z. (2015). Sosyal bilimlerde nitel araştırma yöntemleri. Manevi Temelli Sosyal Hizmet Araştırmaları Dergisi, 1(1), 62-80.

Kocatürk, S. (2016). Hizmetiçi eğitimin çalışan performansına etkisi: Bir meta-analiz çalışması (yayınlanmamıs yükseklisans tezi). Akdeniz Üniversitesi, Antalya.

Köksal, M. S., \& Southerland, S. (2018). Pedagojik hoşnutsuzluk yaşayan fen bilgisi öğretmenleri için araştırma-incelemeye dayalı öğretime yönelik reform odaklı hizmet-içi öğretmen eğitimi girişimlerinin değeri: Bir beklenti-değer bakış açısı. Eğitim ve Bilim, 43(194).157-184. 
Mede, E., \& Iş1k, M. (2016). The Needs of primary english teachers for an in-service teacher training program. Turkish Online Journal of Qualitative Inquiry, 7(2), 1-30.

Ntuli, E. (2018). Instructional Technology Courses in Teacher Education: A Study of Inservice Teachers' Perceptions and Recommendations. International Journal of Information and Communication Technology Education (IJICTE), 14(3), 41-54.

O’Dwyer, J., B., \& Atl1, H., H. (2015). A study of in-service teacher educator roles, with implications for a curriculum for their professional development. European journal of teacher education, $38(1), 4-20$.

Osamwonyi, E., F. (2016). In-Service education of teachers: Overview, problems and the way forward. Journal of Education and Practice, 7(26), 83-87.

Önen, F., Mertoğlu, H., Saka, M., \& Gürdal, A. (2009). Hizmetiçi eğitimin öğretmenlerin öğretim yöntem ve tekniklerine ilişkin bilgilerine etkisi: ÖPYEP örneği. Ahi Evran Üniversitesi Kırşehir Ĕ̈itim Fakültesi Dergisi, 10(3), 9-23.

ÖYGM (2019a). Hizmetiçi Eğitim Enstitüleri. 17.04.2019 tarihinde http://oygm.meb.gov.tr/www/tanitim/icerik/633 adresinden alınmıştır.

ÖYGM (2019b). Geliştirilen ve güncellenen standart kriterlere uygun olarak hazırlanan örnek hizmetiçi eğitim programları. 17.04.2019 tarihinde http://oygm.meb.gov.tr/dosyalar/StPrg/ adresinden alınmiştır.

Özavcı E., Çelikten M. (2017). Öğretmen görüşlerine göre uzaktan hizmet içi eğitim uygulamalarında karş1laş1lan sorunlar ve çözüm. Turkish Journal of Educational Studies, 4 (2),39-76.

Özbek, R., Susam, E., Onat, M., C., \& Özbek, N. (2018). Ortaokul öğretmenlerinin MEB hizmet içi eğitim programlarının etkililiğine ve bu faaliyetlerin yapıldığı yerlere ilişkin görüşleri (Siirt ili örneği). The Journal of International Lingual Social and Educational Sciences, 4(2), 126-134.

Özcan, Ş., \& Bakioğlu, A. (2010). Bir meta analitik etki analizi: Okul yöneticilerinin hizmetiçi eğitim almalarının göreve etkisi. Hacettepe Üniversitesi Eğitim Fakültesi Dergisi, 38(38), 201-212.

Öztürk, M. (2019). An evaluation of an innovative in-service teacher training model in turkey. International Journal of Higher Education, 8(1), 23-36.

Öztürk, M., \& Sancak, S. (2007). Hizmet içi eğitim uygulamalarının çalışma hayatına etkileri. Journal of Yaşar University, 2(7), 761-794.

Öztürk, Ö., \& Öztürk, G. (2019). Music teachers' status of participation in in-service training programs and their expectations. Bartin Üniversitesi Egitim Fakültesi Dergisi, 8(1), 246-257.

Sakkoulis, D. P., Asimaki, A., \& Vergidis, D. K. (2018). In-service training as a factor in the formation of the teacher's individual theory of education. International Education Studies, 11(3), 48-60.

Şahin, Ü., \& Türkoğlu, A. (2017) Sınıf öğretmenlerine yönelik hizmet içi eğitim model önerisi. Mustafa Kemal Üniversitesi Sosyal Bilimler Enstitüsü Dergisi, 14(37), 90-104.

Ulla, M., B., \& Winitkun, D. (2018). In-service teacher training program in Thailand: Teachers' Beliefs, Needs, And Challenges. Pertanika Journal of Social Sciences \& Humanities, 26(3), 1579-1594.

Uysal, H., H. (2012). Evaluation of an in-service training program for primary-school language teachers in Turkey. Australian Journal of Teacher Education, 37(7), 14-29.

Uzunöz, Y., A., A. (2012). Trabzon'da görev yapmakta olan coğrafya öğretmenlerinin hizmetiçi eğitim faaliyetlerinin yeterliliği ile ilgili düşünceleri. Karadeniz İncelemeleri Dergisi, 12(12), 189-202.

Yıldırım, A., \& Şimşek, H. (2006). Sosyal bilimlerde nitel araştırma yöntemleri. Ankara: Seçkin Yayıncilik.

Yılmaz, H., \& Kocasaraç, H. (2010). Hizmetiçi öğretmen eğitiminde yeni bir yaklaşım: Yenilikçi öğretmenler programı ve değerlendirmesi. Ahi Evran Üniversitesi Kırşehir Eğitim Fakültesi Dergisi, 11(3), 51-64.

Yolcu, H., \& Kartal, S. (2017). Evaluating of in-service training activities for teachers in Turkey: A critical analysis. Universal Journal of Educational Research, 5(6), 918-926. 